\title{
ROS-mediated activation and mitochondrial translocation of CaMKII contributes to Drp1-dependent mitochondrial fission and apoptosis in triple-negative breast cancer cells by isorhamnetin and chloroquine
}

Jinjiao Hu${ }^{1 \dagger}$, Yanhao Zhang ${ }^{1 \dagger}$, Xiuxing Jiang ${ }^{1}$, Hongwei Zhang ${ }^{1}$, Ziyi Gao ${ }^{3}$, Yunong Li ${ }^{1}$, Ruoqiu Fu', Lirong Li ${ }^{1}$, Jie Li ${ }^{1}$, Hongjuan Cui ${ }^{4,5^{*}}$ and Ning Gao ${ }^{1,2^{*}}$

\begin{abstract}
Background: Triple-negative breast cancer (TNBC) is often aggressive and associated with a poor prognosis. Due to the lack of available targeted therapies and to problems of resistance with conventional chemotherapeutic agents, finding new treatments for TNBC remains a challenge and a better therapeutic strategy is urgently required.

Methods: TNBC cells and xenograft mice were treated with a combination of chloroquine (CQ) and isorhamnetin $(\mathrm{IH})$. Mitochondrial fission, apoptosis, and related signaling pathways were determined by flow cytometry, immunofluorescence, and related molecular biological techniques.

Results: The inhibition of autophagy/mitophagy by CQ selectively enhances $\mathrm{IH}$-induced mitochondrial fission and apoptosis in TNBC cells but not in estrogen-dependent breast cancer cells. These events were accompanied by mitochondrial translocation of Bax and the release of cytochrome c. Mechanistically, these effects were associated with oxidative stress-mediated phosphorylation of CaMKII (Thr286) and Drp1 (S616), and subsequent mitochondrial translocation of CaMKII and Drp1. The interruption of the CaMKII pathway by genetic approaches (e.g. CaMKII mutant or siRNA) attenuated combination-mediated mitochondrial fission and apoptosis. The combination of CQ/IH was a marked inhibitor tumor growth, inducing apoptosis in the TNBC xenograft mouse model in association with the activation of CaMKIl and Drp1 (S616).
\end{abstract}

Conclusions: Our study highlights the critical role of ROS-mediating CaMKII/Drp1 signaling in the regulation of mitochondrial fission and apoptosis induced by combination of $\mathrm{CQ} / \mathrm{IH}$. These findings also suggest that $\mathrm{IH}$ could potentially be further developed as a novel chemotherapeutic agent. Furthermore, a combination of $\mathrm{IH}$ with classic autophagy/mitophagy inhibitor could represent a novel therapeutic strategy for the treatment of TNBC.

Keywords: Triple-negative breast cancer, Chloroquine, Isorhamnetin, Autophagy, Apoptosis, CaMKII, Drp1

\footnotetext{
* Correspondence: hongjuan.cui@gmail.com; gaoning59@163.com

† Jinjiao Hu and Yanhao Zhang contributed equally to this work.

${ }^{4}$ State Key Laboratory of Silkworm Genome Biology, Southwest University,

2\#Tiansheng Road, Beibei District, Chongqing 400716, China

${ }^{1}$ College of Pharmacy, Army Medical University, 30 Gaotanyan Street,

Shapingba District, Chongqing 400038, China

Full list of author information is available at the end of the article
}

(c) The Author(s). 2019 Open Access This article is distributed under the terms of the Creative Commons Attribution 4.0 International License (http://creativecommons.org/licenses/by/4.0/), which permits unrestricted use, distribution, and reproduction in any medium, provided you give appropriate credit to the original author(s) and the source, provide a link to the Creative Commons license, and indicate if changes were made. The Creative Commons Public Domain Dedication waiver (http://creativecommons.org/publicdomain/zero/1.0/) applies to the data made available in this article, unless otherwise stated. 


\section{Background}

Breast cancer is the most common malignancy and is a leading cause of cancer-related deaths in women worldwide [1]. Among its different subtypes, triple-negative breast cancer (TNBC) accounts for 15-20\% of diagnosed breast tumors, there being a higher incidence in young and African-American women [2, 3]. TNBC constitutes a heterogeneous group of malignancies that are often aggressive and associated with a poor prognosis [4]. Due to a lack of available targeted therapies and to problems of resistance to conventional chemotherapeutic agents, finding new treatments for TNBC remains a challenge; a better therapeutic strategy is urgently required $[5,6]$.

Autophagy is a mechanism by which cellular material is delivered to lysosomes for degradation [7]. Autophagy acts as pro-survival pathway in cancer cells by promoting the viability and growth of these cells and imparts resistance in them to many chemotherapeutic agents in tumor cells, including TNBC cells [8]. Therefore, autophagy inhibition has been regarded as a promising therapeutic approach in the treatment of TNBC and other cancers. Recent evidence reveals that the inhibition of autophagy has been identified as a potential adjunctive strategy for enhancing the chemotherapeutic effect [9]. The antimalaria drugs chloroquine (CQ) and hydroxychloroquine (HCQ) are currently the only clinically-available drugs that inhibit autophagy. Extensive preclinical evidence reveals that the inhibition of autophagy by CQ or HCQ increases the potential of anticancer chemotherapeutic agents such as the antiretroviral Nelfinavir and the COX2 inhibitor Celecoxib in TNBC [10]. The current study reveals that the inhibition of autophagy by CQ could enhance the effects of chemotherapeutic agents in treating TNBC patients with high LC3B protein levels [11]. Owing to the limitations of current chemotherapeutic agents in the treatment of TNBC, it is important to develop novel and efficacious chemotherapeutic agents that target TNBCs.

Isorhamnetin (IH), also called 3-O-methylquercetin (Fig. 1a), is a flavonoid that is present in plants of the Polygonaceae family; it is also an immediate metabolite of quercetin in mammals [12]. IH has received attention due to its antitumor properties in cancers such as lung, esophageal, gastric, colorectal, skin, and breast cancers [13-18]. IH has displayed a diversity of anti-tumor activities, including inhibiting migration and invasion, inhibiting cell proliferation, and the induction of apoptosis through various signaling pathways (e.g. p38/STAT3, MEK, Akt/mTOR). It has recently been shown that IH induces autophagy in human breast cancer cells through modulating the PI3K/AKT/mTOR/p70S6K/ULK signaling pathway [19]. Yuan Y, et al. reported that the inhibition of autophagy by $\mathrm{CQ}$ enhances $\mathrm{IH}$-induced mitochondriadependent apoptosis in non-small lung cancer cells.
However, the precise mechanism by which the inhibition of autophagy potentiates $\mathrm{IH}$-induced mitochondrial apoptosis in breast cancer cells remains unclear.

In this study, we discovered that the inhibition of autophagy/mitophagy by CQ selectively enhances IH-induced mitochondrial fission and apoptosis in TNBC cells but not in estrogen-dependent breast cancer cells. Mechanistically, this effect is mediated by oxidative stress-phosphorylated $\mathrm{Ca}^{2+} /$ calmodulin-dependent kinase II (CaMKII) (Thr286) and Drp1 (S616) and, subsequently, their mitochondrial translocation. Our data identify autophagy as a novel prognostic marker for TNBC: a combination of $\mathrm{IH}$ with CQ could represent a novel therapeutic strategy for treating TNBC.

\section{Material and methods}

\section{Chemicals and antibodies}

Isorhamnetin was purchased from Must Biotechnology (Chengdu, China); chloroquine from Sigma-Aldrich; Mn-TBAP from Focus Biomolecules; apocynin was purchased from Selleck Chemicals (Shanghai, CA). The antibodies against cleaved-caspase 3 (9661), pro-caspase 3 (9668S), p62 (5114S), phospho-CamkII (T286, 12,716), phospho-Drp1 (S616, 3455), phospho-Drp1 (S637, 4876), and Drp1 (8570) were purchased from Cell Signaling Technology; PARP (1078-1) was purchased from Epitomics; $\beta$-actin (A1978) and LC3 (L754S) from Sigma-Aldrich; Bax (510804), Cleaved-PARP (380374), Bak (380976), NOX2 (381293), NOX4 (380874) and COX IV (200147) from Zen-Bio. Cytochrome. C (13156) and CamkII (5306) were purchased Santa Cruz Biotechnology.

\section{Cell culture}

MDA-MB-231 and MCF-7 cells were cultured in DMEM medium; BT549 cells in RPMI 1640 medium; MCF-10A in MEBM medium. All media comprised $10 \%$ fetal bovine serum (FBS) and antibiotics. All cell lines were obtained from the American Type Culture Collection (ATCC, Manassas, VA) and cultured at $37^{\circ} \mathrm{C}$ in a humidified atmosphere with $5 \% \mathrm{CO}_{2}$.

\section{Cell viability (MTT) assay}

Cells were seeded in 96 well plates $\left(3.5 \times 10^{3}\right.$ per each well). After treatment, $20 \mu \mathrm{l} \mathrm{MTT}(5 \mathrm{mg} / \mathrm{ml})$ was added in each well and incubated at $37^{\circ} \mathrm{C}$ for $4 \mathrm{~h}$. After the medium was discarded, each well was supplemented with $150 \mu \mathrm{l}$ DMSO to dissolve the formazan before being measured by a microplate reader at $490 \mathrm{~nm}$. The cell viabilities were normalized to the control group.

\section{Soft agar assay}

Sustainment gel was mixed with $0.6 \%$ agarose (Sigma-Aldrich) in a cell culture medium in 12 well plates. One-thousand cells were cultured in cultivate gel 


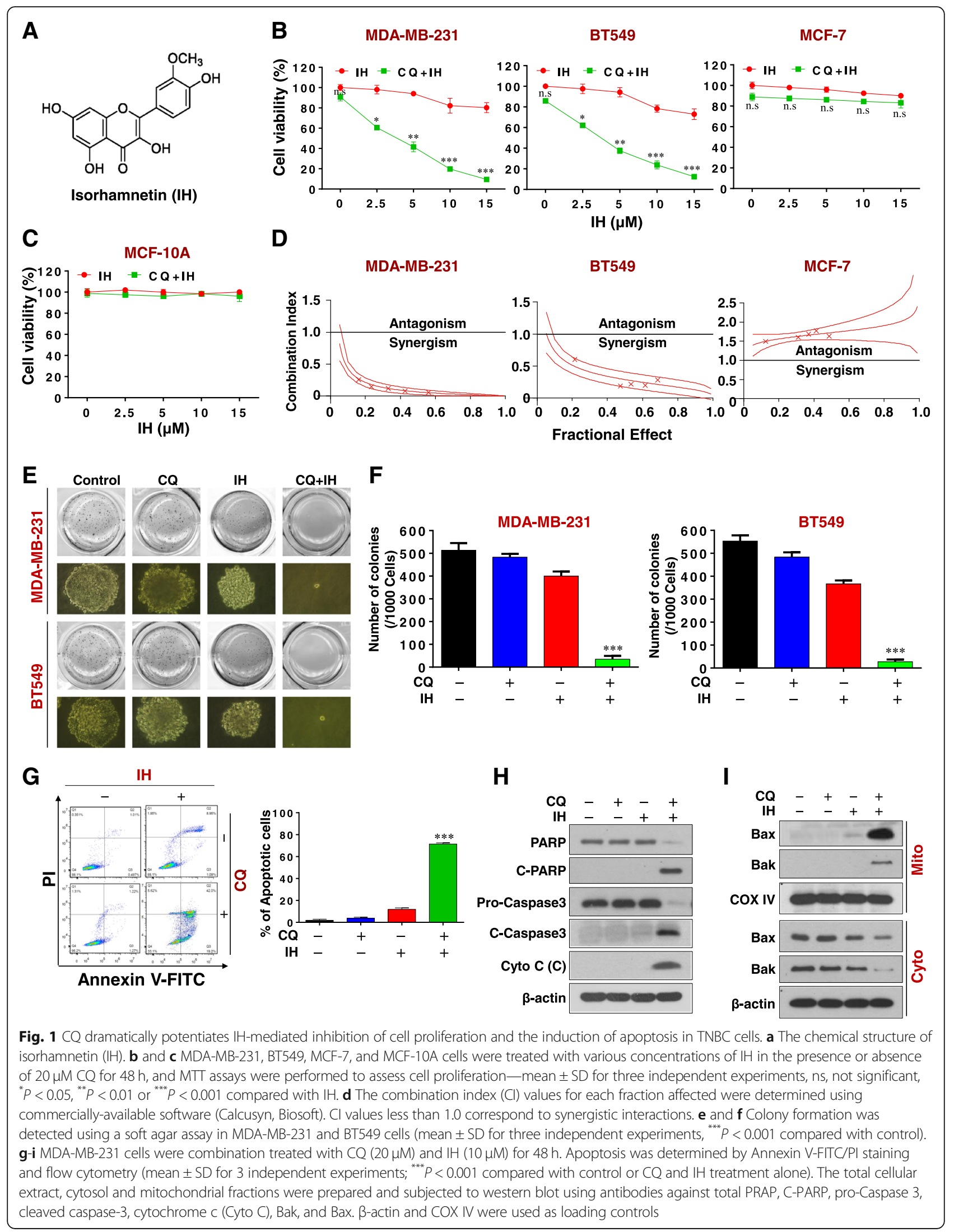


above concretionary sustainment gel (mixed with $0.3 \%$ agarose in cell culture medium with 10\% FBS). After 28 days, the colonies were counted and photographed.

\section{Apoptosis assay}

Apoptosis was examined by flow cytometry according to the manufacturer's instructions (BD Biosciences PharMingen). In summary, $1 \times 10^{6}$ cells were washed twice with phosphate-buffered saline (PBS) and stained with $5 \mu \mathrm{l}$ Annexin V-FITC and $10 \mu \mathrm{l}$ PI for $15 \mathrm{~min}$ at room temperature in the dark. Quantification of apoptotic cells was performed by flow cytometry using a FACScan cytofluorometer (BD Biosciences). Both early (Annexin V-positive, PI-negative) and late (Annexin V-positive and PI-positive) apoptotic cells were included in the cell death determinations.

\section{Mitochondrial and cytosolic fractionation}

Mitochondrial and cytosolic fractionation were obtained as previously described [20]. In summary, cell pellets were washed twice with PBS and resuspended in $5 \times$ Buffer A (20 mM HEPES, $10 \mathrm{mM} \mathrm{KCl,} 1.5 \mathrm{mM} \mathrm{MgCl}_{2}, 1$ mM EDTA, $1 \mathrm{mM}$ EGTA, $1 \mathrm{mM} \mathrm{Na} \mathrm{VO}_{4}$ ). Cells were homogenized by passing them 15 times through a 22 -gauge needle. The homogenate was centrifuged at $1000 \mathrm{~g}$ at $4{ }^{\circ} \mathrm{C}$ for $10 \mathrm{~min}$. The supernatant was then transferred and continued being centrifuged at $3500 \mathrm{~g}$ at $4{ }^{\circ} \mathrm{C}$ for $10 \mathrm{~min}$. The pellet fraction was considered the "mitochondrial" fraction. The supernatant fraction was then centrifuged at $120000 \mathrm{~g}$ at $4{ }^{\circ} \mathrm{C}$ for $10 \mathrm{~min}$; the supernatant fraction was then considered the "cytosolic" fraction.

\section{Western blot and immunoprecipitation}

The protein samples $(30-50 \mu \mathrm{g})$ were separated using SDS-PAGE and transferred to PVDF membranes (Bio-Rad, 162-0177). After blocking with 5\% fat-free dry milk in $1 \times$ Tris-buffered saline (TBS), the membrane was probed overnight with primary antibodies at $4{ }^{\circ} \mathrm{C}$. Protein bands were detected by incubating with horseradish peroxidase-conjugated antibodies (Kirkegaard and Perry Laboratories, Gaithersburg, MD, USA) and visualized with enhanced chemiluminescence reagent (Perkin-Elmer, Boston, MA, USA). For immunoprecipitation analysis, equal quantities of proteins were incubated with primary antibodies at $4{ }^{\circ} \mathrm{C}$ on a rocking platform. Immune complexes were collected with protein $\mathrm{A} / \mathrm{G}$ agarose beads (Beyotime Technology), washed in PBS five times, and subjected to Western blot.

\section{Detection of calcium ion level}

The $\mathrm{Ca}^{2+}$ level was determined by using the fluorescent dye Fluo-4/AM (Invitrogen). Briefly, cells were washed three times with HBSS, then incubated with $4 \mu \mathrm{M}$
Fluo-4/AM (diluted with $\mathrm{HBSS}$ ) at $37^{\circ} \mathrm{C}$ for $30 \mathrm{~min}$. After being washed twice with HBSS, followed by an additional 15 -min incubation at $37^{\circ} \mathrm{C}$ to allow complete de-esterification of intracellular AM esters, the cells were detected by flow cytometry using a FACScan cytofluorometer (BD Biosciences).

\section{Immunofluorescence}

Cells were seeded on coverslips and cultured in 24 well plates for $24 \mathrm{~h}$. After treatment for $24 \mathrm{~h}$, mitochondria were stained with MitoTracker Deep Red FM (Molecular Probes, Carlsbad, USA) according to the manufacturer's instructions. Cells were fixed with $4 \%$ formaldehyde (Beyotime Biotechnology) for $30 \mathrm{~min}$, permeabilized with $0.1 \%$ Triton X-100 in PBS for $5 \mathrm{~min}$, and then blocked with goat serum (Beyotime Biotechnology) in PBS for 30 min. The cells were incubated overnight with primary antibodies at $4{ }^{\circ} \mathrm{C}$, followed by the appropriate secondary antibodies at $37^{\circ} \mathrm{C}$ for $1 \mathrm{~h}$. The cells were viewed using a laser-scanning confocal microscope (Zeiss, Germany). All images were analyzed by ImageJ software (MD, USA).

\section{Detection of intracellular ROS}

Intracellular production of ROS was measured using DCFH-DA. To determine ROS production, cells were incubated with DCFH-DA $(10 \mu \mathrm{M})$ for $30 \mathrm{~min}$, washed twice with cold PBS and detected by flow cytometry using a FACScan cytofluorometer (BD Biosciences).

\section{RNA interference and site mutant}

The target sequence of CamkII shRNA (5'-CGTA AATGGATTTCGCGTTAA-3') was constructed by Gene Chem Co. Ltd. (Shanghai, China). To generate CamkII knockdown stable cell lines, a lentiviral system was employed as previously described [21]. Briefly, 293FT cells were co-transfected with lentiviral packing vectors $\mathrm{pLP} 1, \mathrm{pLP} 2$ and $\mathrm{pLP} / \mathrm{VSVG}$ (Invitrogen), along with shCamkII or shCon plasmid, using Lipofectamine 3000 (Invitrogen) for $48 \mathrm{~h}$. The supernatant containing the lentivirus was harvested and used for infection with MDA-MB-231 cells. The cells were subsequently selected with $8 \mu \mathrm{g} / \mathrm{mL}$ puromycin to establish stable cell lines. Site mutant plasmids of CamkII (CamkII ${ }^{\mathrm{T} 286 \mathrm{~A}}$ and CamkII ${ }^{\mathrm{T} 286 \mathrm{D}}$ ) were constructed by Gene Chem Co. Ltd. (Shanghai, China). The sequence of primers for $\mathrm{CamkII}{ }^{\mathrm{T} 286 \mathrm{~A}}$ were forward 5'-CACAGACAGGAGGCCGTGGACTGCCTG-3', and reverse 3'-GTGTCTGTCCTCCGGCACCTGACGGAC-5' .

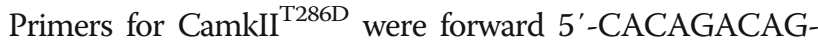
GAGGATGTGGACTGCCTG-3', and reverse 3'-GTGT CTGTCCTCCTACACCTGACGGAC-5'. MDA-MB-231 cells were transfected with $\mathrm{CamkII}{ }^{\mathrm{T} 286 \mathrm{~A}}$ and $\mathrm{CamkII}{ }^{\mathrm{T} 286 \mathrm{D}}$ using Lipofectamine 3000 according to the manufacturer's instructions. 


\section{Xenograft assay}

Female nude mice (5-6 weeks old) were purchased from Vital River Laboratories (VRL, Beijing, China) and fed a standard animal diet and water. The animal studies were approved by the University Institutional Animal Care and Use Committee. MDA-MB-231 cells were suspended in a 1:1 ratio in DMEM medium with a Matrigel basement membrane matrix (Sigma, E1270). Cells $\left(4 \times 10^{7}\right)$ were inoculated in the right legs of mice. After tumor inoculation, the mice were randomly divided into four treatment groups (16 mice per group; six mice were used for body weight and tumor volume measurement, the others for survival analysis). The mice were treated with either vehicle, CQ $(40 \mathrm{mg} / \mathrm{kg})$ or IH $(20 \mathrm{mg} / \mathrm{kg})$, or a combination of $\mathrm{CQ} / \mathrm{IH}$ by intraperitoneal injection once every 2 days. The body weight and tumor volume $\left(\mathrm{mm}^{3}\right)$ were measured. The mice were euthanized 30 days after medication, the tumors were excised and were either formalin-fixed or flash-frozen at $-20^{\circ} \mathrm{C}$. $\mathrm{H} \& \mathrm{E}$, TUNEL, and immunohistochemical analyses were performed as previously described [22].

\section{Statistical analysis}

All data values are represented as mean \pm SD. The comparisons were performed using Student's t-test or one-way analysis of variance (ANOVA). Survival analysis in vivo was performed using the Kaplan-Meier method and significance was calculated using the log-rank test. $" P<0.05, " P<0.01$, and ${ }^{* * * *} P<0.001$ were regarded as significant differences.

\section{Results}

Chloroquine dramatically potentiates isorhamnetinmediated inhibition of cell proliferation and induction of apoptosis in triple negative breast cancer cells

The effects of combined treatment with $\mathrm{CQ}$ and $\mathrm{IH}$ on cell viability were first investigated in multiple human breast cancer cell lines. Exposure to a subtoxic concentration of CQ $(20 \mu \mathrm{M})$ significantly decreased the cell viability in both triple negative breast cancer MDA-MB-231 and BT549 cells treated with a nontoxic concentration of IH $(2.5 \mu \mathrm{M})$, and the degree of potentiation increased as concentrations increased (Fig. 1b). In contrast, $\mathrm{CQ}$ in combination with $\mathrm{IH}$ exerted little effect on cell viability toward MCF-7 (estrogen-dependent) cells (Fig. 1b) and normal breast epithelial MCF-10A cells (Fig. 1c). The median dose effect analysis of cell viability in cells exposed to CQ and $\mathrm{IH}$ for $48 \mathrm{~h}$ at fixed ratios yielded $\mathrm{CI}$ values consistently less than 1.0 in MDA-MB-231 and BT549 cells but greater than 1.0 in MCF-7 cells (Fig. 1d). We also examined the effects of $\mathrm{CQ} / \mathrm{IH}$ on colony formation in both MDA-MB-231 and BT549 cells in vitro by using soft agar assay. As shown in Fig. 1e and $\mathrm{f}$, the combination of $\mathrm{CQ} / \mathrm{IH}$ significantly decreased the number of colonies in MDA-MB-231 and BT549 cells. These results indicate that the combination of $\mathrm{CQ} / \mathrm{IH}$ selectively inhibits cell proliferation and tumorigenesis in TNBC cells.

We next investigated the synergistic effects of $\mathrm{CQ} / \mathrm{IH}$ on apoptosis in MDA-MB-231 and BT549 cells. Combined treatment with minimally-toxic concentrations of CQ $(20 \mu \mathrm{M})$ and IH $(10 \mu \mathrm{m})$ resulted in a pronounced increase in apoptosis in MDA-MB-231 and BT549 cells (Fig. 1g and Additional file 1: Figure S1A). Consistent with these findings, the same CQ and IH concentrations resulted in a degradation of PARP, cleavage/activation of caspases-3 and release of cytochrome $\mathrm{c}$ into the cytosolic fraction (Figs. 1h and Additional file 1: Figure S1B). The translocation of Bax and Bak from the cytosol to the mitochondria was also noted in cells treated with a combination of $\mathrm{CQ} / \mathrm{IH}$ (Fig. 1i and Additional file 1: Figure $\mathrm{S} 1 \mathrm{C})$. Together, these findings indicate that CQ interacts synergistically with $\mathrm{IH}$ to selectively induce mitochondrial injury and apoptosis in TNBC cells.

\section{Excessive accumulation of mitophagosomes contributes to mitochondrial injury and apoptosis mediated by a combination of $\mathrm{CQ}$ and $\mathrm{IH}$}

Since CQ suppresses autophagic flux by blocking autophagosome-lysosome fusion, we subsequently investigated the effects of the combination of $\mathrm{CQ} / \mathrm{IH}$ on the accumulation of mitophagosomes. As shown in Fig. 2a, treating cells with $\mathrm{CQ}$ alone resulted in the accumulation of LC3B-II and p62 in mitochondria. Treating cells with $\mathrm{IH}$, an autophagy inducer [19], resulted in modest increases in levels of LC3B-II and decreases in levels of p62 in mitochondria. Joint treatment with $\mathrm{CQ} / \mathrm{IH}$ resulted in excessive accumulation of LC3B-II and p62 in mitochondria. Similarly, significant increases in colocalization of GFP-LC3 and RFP-Mito were observed in cells combined-treated with $\mathrm{CQ} / \mathrm{IH}$ (Fig. 2b), suggesting that excessive accumulation of mitophagosomes may be involved in mitochondrial injury and apoptosis in cells treated with a combination of $\mathrm{CQ} / \mathrm{IH}$. To test this possibility, a siRNA approach was used to stably knock down ATG5 expression (Fig. 2c). Knockdown of ATG5 markedly reduced combination-mediated LC3B-II accumulation in mitochondria (Fig. 2d) and mitophagosome formation (Fig. 2e). Knockdown of ATG5 also abrogated combination-mediated degradation of PARP, cleavage/ activation of caspase- 3 and cytochrome c release (Fig. 2f), as well as apoptosis (Fig. $2 \mathrm{~g}$ and Additional file 1: Figure S2). Together, these findings indicate that the excessive accumulation of mitophagosomes is implicated in mitochondrial injury and apoptosis mediated by the combination of $\mathrm{CQ} / \mathrm{IH}$ in TNBC cells. 


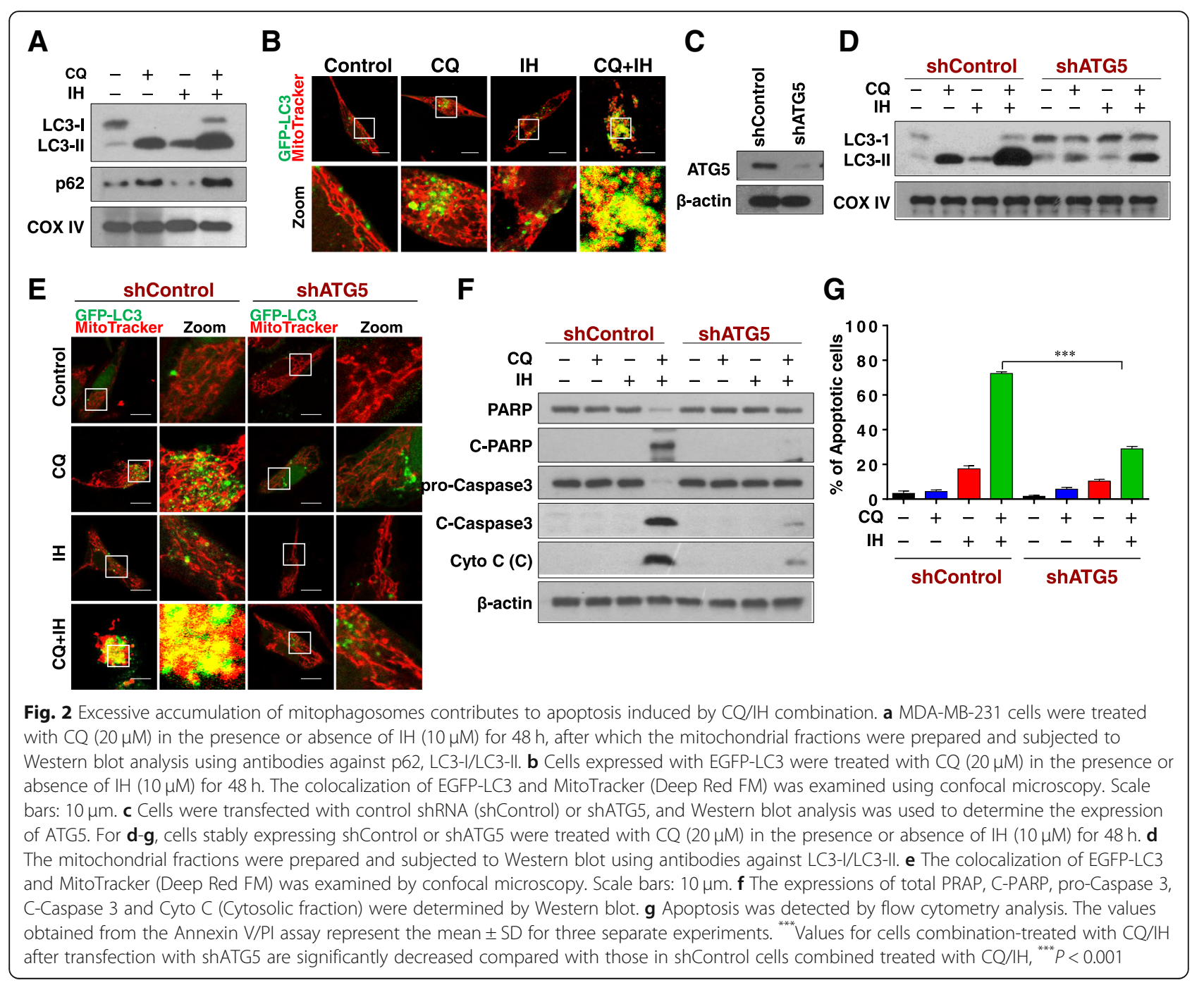

The combination of $\mathrm{CQ} / \mathrm{IH}$ induces mitochondrial fission through phosphorylation of Camkll (Thr286) and Drp1 (Ser616) and their mitochondrial translocation Recent studies indicate that mitochondrial fission participates in Bax-mediated permeabilization of the outer mitochondrial membrane and cytochrome c release [23]. Therefore, we next examined the effects of the combination of $\mathrm{CQ} / \mathrm{IH}$ on mitochondrial dynamics using MitoTracker Red CMXRos. The combination of $\mathrm{CQ} / \mathrm{IH}$ resulted in a significant increase in the proportion of cells with fragmented mitochondria (Fig. 3a and b, Additional file 1: Figure S3A and S3B).

Increasing evidence reveals that phosphorylation of Drp1 (Ser 616) or dephosphorylation of Drp1 (Ser 637) plays a critical role in the regulation of mitochondrial fission through its mitochondrial translocation [24]. We then examined the effects of the combination of $\mathrm{CQ} / \mathrm{IH}$ on the phosphorylation of Drp1 at Ser637 and Ser616, and the mitochondrial translocation of Drp1. Combined treatment with $\mathrm{CQ} / \mathrm{IH}$ increased levels of phospho-Drp1
(Ser 616) but had no effect on the phosphorylation of Drp1 at Ser 637 (Fig. 3c, Additional file 1: Figure S3C). The combination of $\mathrm{CQ} / \mathrm{IH}$ also led to the mitochondrial translocation of Drp1 (Fig. 3c, Additional file 1: Figure S3C). Immunofluorescence analysis showed the Drp1 signal in the mitochondria of cells treated with a combination of $\mathrm{CQ} / \mathrm{IH}$ (Fig. 3d, Additional file 1: Figure S3D). Since the colocalization of Drp1 and Bax at the mitochondrial fission site is required for mitochondrial fission and apoptosis [25], we next examined the effect of a combination of $\mathrm{CQ} / \mathrm{IH}$ on the colocalization of Drp1 and Bax in mitochondria by using immunofluorescence analysis. The colocalization of Drp1 and Bax in mitochondria was observed in cells treated with a $\mathrm{CQ}$ / $\mathrm{IH}$ combination (Additional file 1: Figure S4). These results support the proposition that the phosphorylation of Drp1 at the S616 site promotes its mitochondrial translocation, leading to mitochondrial fission and apoptosis through the colocalization of Drp1 and Bax in response to a combination of $\mathrm{CQ} / \mathrm{IH}$. 


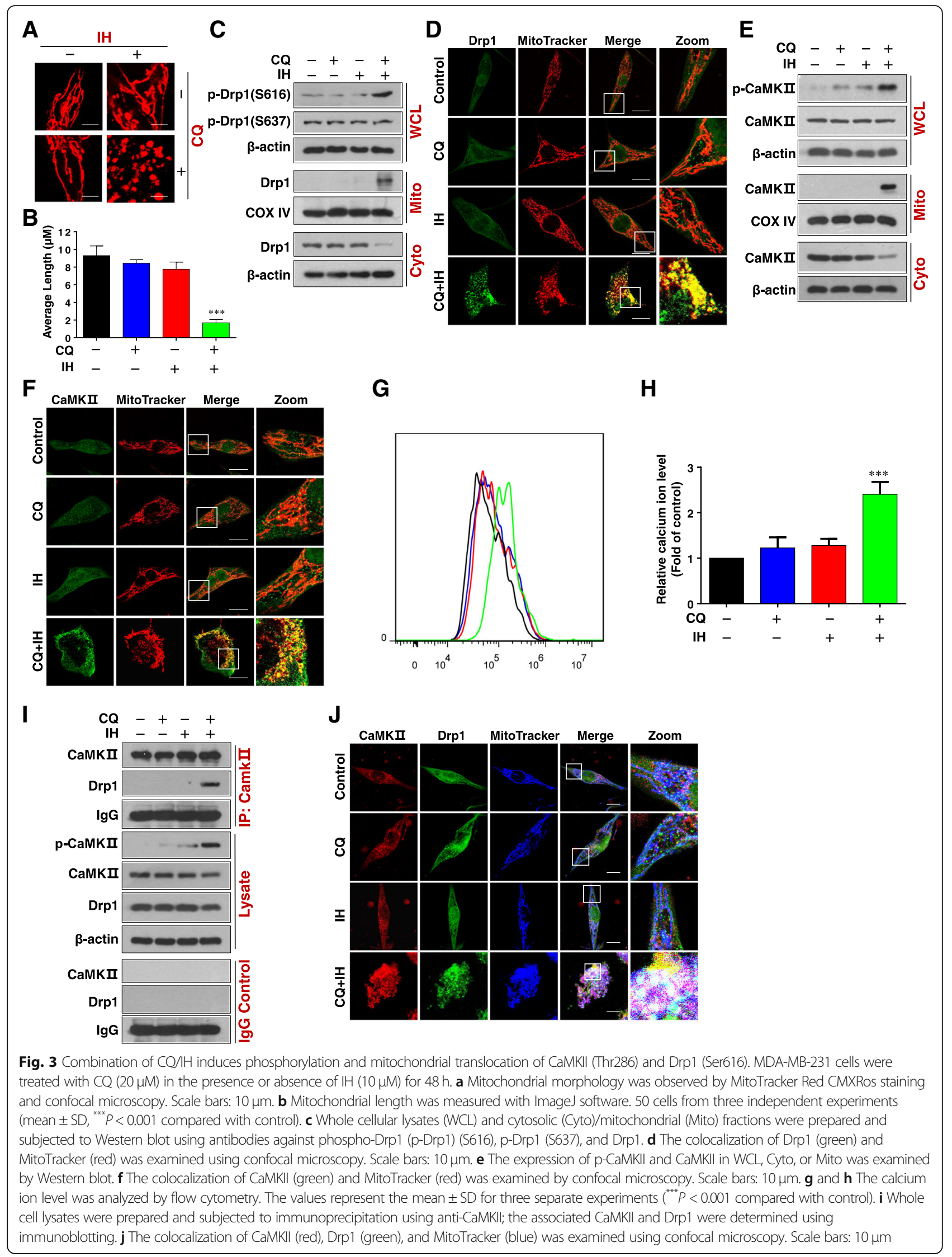


Recent evidence reveals that the phosphorylation of Drp1 at S616 site promotes its mitochondrial translocation upon activation by $\mathrm{Ca}^{2+} /$ calmodulin-dependent kinase II (CaMKII) [26]. We next examined the effects of the $\mathrm{CQ} / \mathrm{IH}$ combination on the phosphorylation of CaMKII (Thr286). Exposure to the $\mathrm{CQ} / \mathrm{IH}$ combination resulted in marked increases in levels of phosphor-CaMKII (Thr286). However, this increase was not present when the agents were administered individually (Fig. 3e, Additional file 1: Figure S5A). Interestingly, combined treatment with CQ/ $\mathrm{IH}$ led to a decrease in the levels of CaMKII in cytosol and increased levels of CaMKII in mitochondria (Fig. 3e, Additional file 1: Figure S5A). Similarly, immunofluorescence analysis showed the CaMKII signal in the mitochondria in the cells that were treated with a combination of $\mathrm{CQ} / \mathrm{IH}$ (Fig. 3f, Additional file 1: Figure S5B). Such findings suggest that the phosphorylation of CaMKII promotes its mitochondrial translocation in response to a combination of $\mathrm{CQ} / \mathrm{IH}$.

Since CaMKII was regulated by calcium ions [27], we next determined the levels of intracellular calcium ions by using the fluorescent calcium indicator Fluo-4/AM. As shown in Fig. 3g and h, the combination of $\mathrm{CQ} / \mathrm{IH}$ significantly increased the levels of intracellular calcium ions in MDA-MB-231 cells.

Since phosphorylation of Drp1 (S616) can be modulated by kinases/phosphatases including CaMKII, it is critical to determine whether CaMKII can directly bind Drp1. Immunoprecipitation analysis showed that combined treatment with $\mathrm{CQ} / \mathrm{IH}$ resulted in increased interaction of CaMKII and Drp1 (Fig. 3i, Additional file 1: Figure S5C). Immunofluorescence analysis also showed the colocalization of MitoTracker with CaMKII and Drp1 in cells treated with a combination of $\mathrm{CQ} / \mathrm{IH}$ (Fig. 3j, Additional file 1: Figure S5D). Taken together, these findings suggest that a combination of $\mathrm{CQ} / \mathrm{IH}$ induces mitochondrial fission through the activation of CaMKII and its mitochondrial translocation, leading to the phosphorylation and mitochondrial translocation of Drp1.

\section{Genetic interruption of CaMKII abrogates mitochondrial fission and apoptosis induced by CQ/IH}

In order to further investigate the role of CaMKII phosphorylation at Thr286 in mitochondrial fission and apoptosis induced by the combination of $\mathrm{CQ} / \mathrm{IH}$, we generated a mutant of CaMKII ${ }^{\mathrm{T} 286 \mathrm{~A}}$ to occlude Thr286 phosphorylation or a mutant of CaMKII ${ }^{\mathrm{T} 286 \mathrm{D}}$ to mimic Thr286 phosphorylation (Fig. 4a). Overexpression of CaMKII ${ }^{\mathrm{T} 286 \mathrm{~A}}$ blocked the phosphorylation of CaMKII (Thr286)/Drp1 (S616) and the mitochondrial translocation of CaMKII/ Drp1 in cells treated with a combination of $\mathrm{CQ} / \mathrm{IH}$. On the other hand, an overexpression of CaMKII ${ }^{\mathrm{T} 286 \mathrm{D}}$ promoted the phosphorylation of CaMKII (Thr286)/Drp1 (S616) and the mitochondrial translocation of CaMKII/
Drp1 in cells treated with either CQ or IH alone or a combination of these (Fig. 4a). CaMKII ${ }^{\mathrm{T} 286 \mathrm{~A}}$ also blocked the colocalization of MitoTracker with CaMKII and Drp1 in cells treated with combination, whereas $\mathrm{CaMKII}^{\mathrm{T} 286 \mathrm{D}}$ increased the colocalization of MitoTracker with CaMKII and Drp1 in cells treated with either CQ or IH alone or a combination of these (Fig. 4b). Furthermore, CaMKII ${ }^{\mathrm{T} 286 \mathrm{~A}}$ attenuated mitochondrial fission, the mitochondrial translocation of Bax, the activation of caspase-3, the release of cytochrome c, and apoptosis induced by combination, whereas CaMKII ${ }^{\mathrm{T} 286 \mathrm{D}}$ promoted these events mediated by either $\mathrm{CQ}$ or IH alone or their combination (Fig. 4c, Additional file 1: Figure S6A-S6D). Thus, our data indicate that the phosphorylation and mitochondrial translocation of CaMKII play critical roles in mitochondrial fission and apoptosis induced by a combination of $\mathrm{CQ} / \mathrm{IH}$.

To further investigate the functional significance of CaM$\mathrm{KII}$ activation in $\mathrm{CQ} / \mathrm{IH}$-mediated mitochondrial fission and apoptosis, a siRNA approach was used to knock down CaMKII expression in a stable way (Additional file 1: Figure S7A). The knockdown of CaMKII blocked phosphorylation of CaMKII (T286)/Drp1 (S616) and mitochondrial translocation of CaMKII/Drp1 that was mediated by a combination of CQ/IH (Fig. 4d). This knockdown of CaMKII also blocked the colocalization of MitoTracker with CaMKII and Drp1 in cells treated with the combination (Fig. 4e). In addition, the knockdown of CaMKII blocked mitochondrial fission, the mitochondrial translocation of Bax, the activation of caspase- 3 , the release of cytochrome c, and apoptosis induced by combination (Fig. 4f, Additional file 1: Figure S7B-S7E). These results further identified the functional role of CaMKII in $\mathrm{CQ} / \mathrm{IH}$-mediated mitochondrial fission and apoptosis.

\section{Combined treatment with $\mathrm{CQ} / \mathrm{IH}$ induces generation of reactive oxygen species}

Several types of evidence have demonstrated that activation of CaMKII is attributable to excessive production of reactive oxygen species (ROS) $[28,29]$. We thus examined the effects of the $\mathrm{CQ} / \mathrm{IH}$ combination on the generation of ROS in MDA-MB-231 and BT549 cells. By using flow cytometry analysis, we found that combined exposure of cells to $\mathrm{CQ} / \mathrm{IH}$ resulted in significant increases in the generation of ROS (Fig. 5a, Additional file 1: Figure S8A). ROS-including superoxide radical $\left(\mathrm{O}_{2}{ }^{\circ-}\right)$, hydrogen peroxide $\left(\mathrm{H}_{2} \mathrm{O}_{2}\right)$, and hydroxyl radical $\left(\mathrm{OH}_{\bullet}\right)_{\text {- }}$ are recognized as signaling molecules that are mobilized in response to various stimuli [30]. To explore further the role of individual ROS on combination-mediated mitochondrial fission and apoptosis, we employed three antioxidants-TBAP (a cell permeable SOD mimetic), catalase, and sodium formate-which primarily act on $\mathrm{O}_{2}{ }^{{ }^{-}}, \mathrm{H}_{2} \mathrm{O}_{2}$, and $\mathrm{OH} \bullet$, respectively. Pretreatment with TBAP, an $\mathrm{O}_{2}{ }^{*-}$ scavenger, 


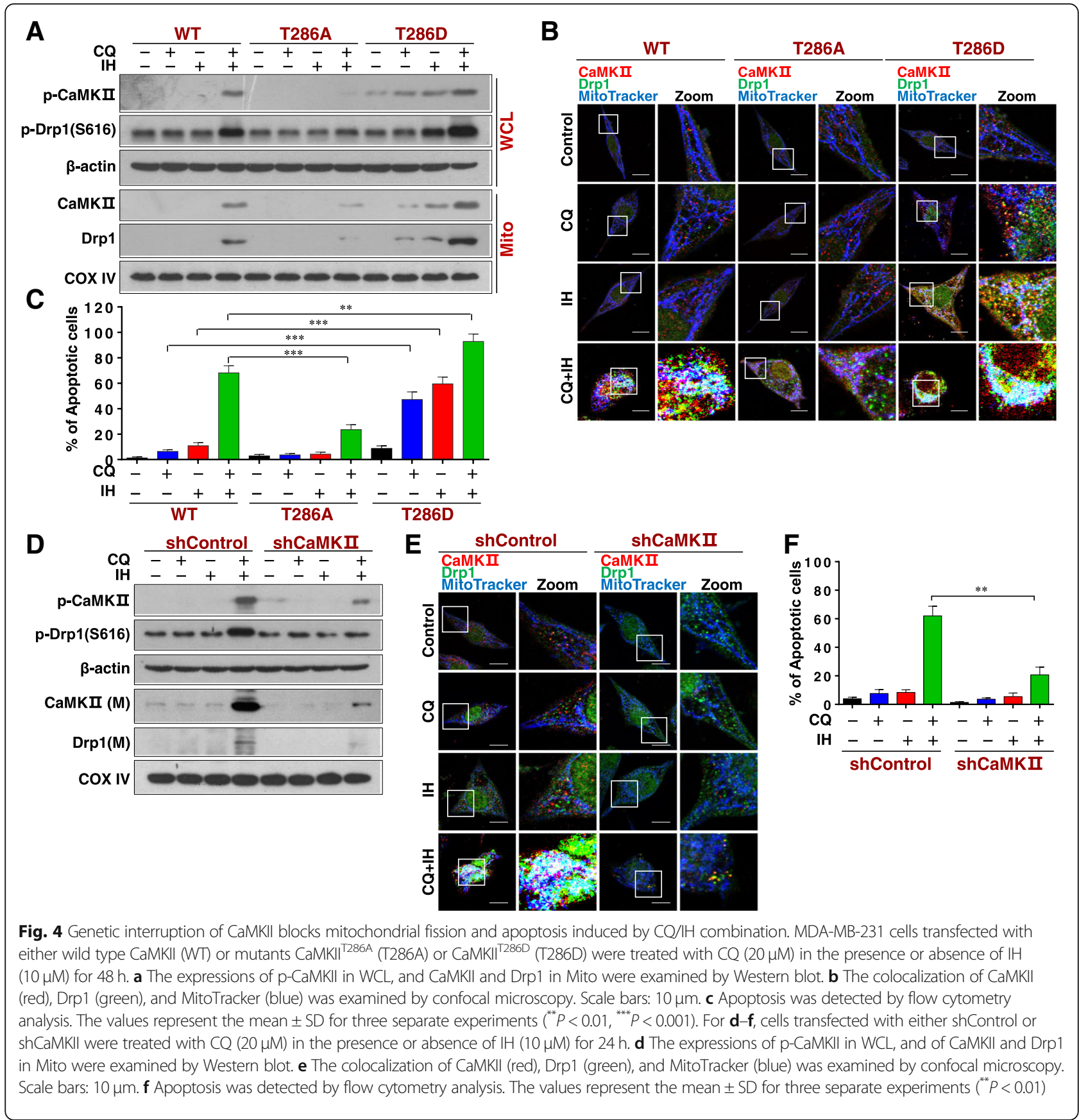

abrogated combination-mediated ROS generation in both MDA-MB-231 and BT549 cells. In contrast, catalase (a $\mathrm{H}_{2} \mathrm{O}_{2}$ scavenger) and sodium formate (an $\mathrm{OH} \bullet$ scavenger) failed to block combination-mediated ROS generation in these cells (Fig. 5b, Additional file 1: Figure S8B). Attempts were then made to assess the functional significance of ROS in combination-induced mitochondrial fission and apoptosis. The addition of TBAP (but not of catalase and sodium formate) essentially abrogated the combination-mediated phosphorylation of CaMKII (T286)/Drp1 (S616) and the mitochondrial translocation of CaMKII/Drp1 (Fig. 5c). Pretreatment with TBAP also abrogated combination-mediated colocalization of MitoTracker with CaMKII and Drp1 (Fig. 5d). Furthermore, the addition of TBAP markedly abrogated combination-induced mitochondrial fission (Fig. 5e and f). Finally, the addition of TBAP significantly abrogated the combination-mediated mitochondrial translocation of Bax and Bak, the degradation of PARP, the activation of caspase 3, the release of cytochrome c, and apoptosis (Fig. $5 \mathrm{~g}$ and h, Additional file 1: Figure S8C). Collectively, these finding suggest that ROS, particularly $\mathrm{O}_{2}{ }^{*-}$ radical, are 


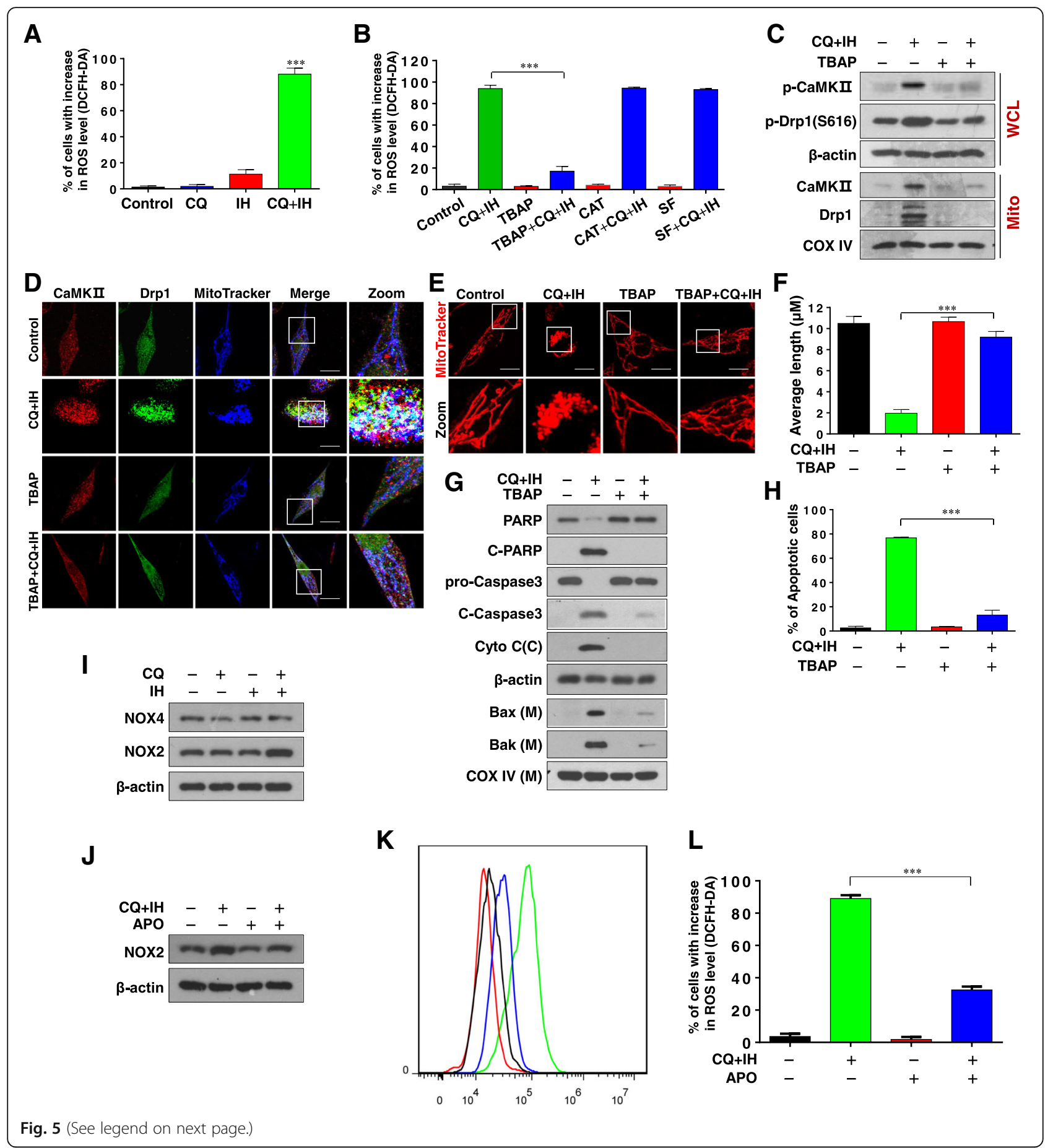




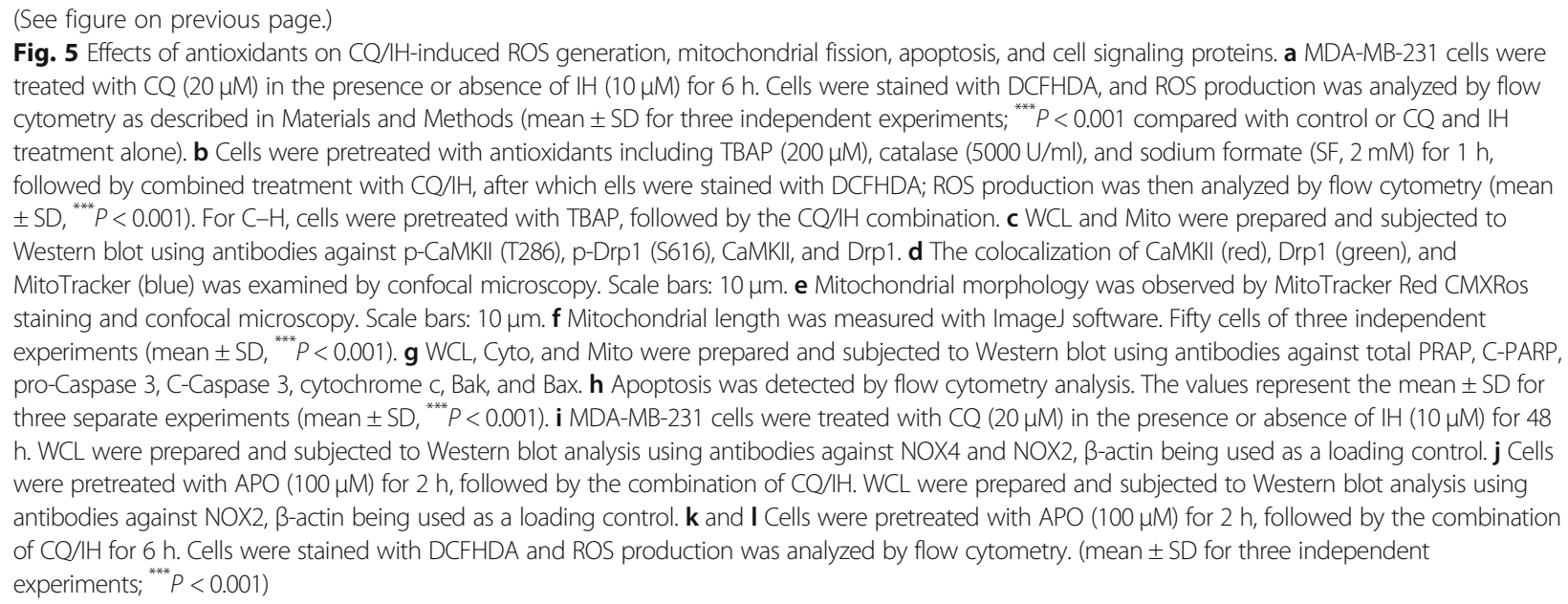

primarily responsible for combination-induced mitochondrial fission and apoptosis through perturbations in CaMKII/Drp1 signaling events.

Increasing evidence indicates that $\mathrm{NADPH}$ oxidase (NOX) is a major source of superoxide anion radical $\left(\mathrm{O}_{2}{ }^{-*}\right)$ generation, and that NOX2 and NOX4 are key enzymes responsible for the oxidative burst [31, 32]. Therefore, we next examined the effect of a combination of $\mathrm{CQ} / \mathrm{IH}$ on the expression of NOX2 and NOX4. As shown in Fig. 5i, a $\mathrm{CQ} / \mathrm{IH}$ combination increased the levels of NOX2 but had no effect on NOX4. In addition, pretreatment with apocynin, a selective NADPH oxidase inhibitor, abrogated combination-induced NOX2 expression and ROS generation (Fig. 5j, k and l).

\section{Inhibition of mitophagy enhances the inhibitory effect of IH on tumor growth in a TNBC xenograft mouse model in vivo}

To determine whether our in vitro findings that the inhibition of autophagy by CQ can be sensitized to IH-induced cell death could be replicated in vivo, we next examined the effect of CQ on the inhibitory efficacy of IH in vivo using a TNBC xenograft mouse model. After inoculation, mice received injections of either vehicle, CQ $(40 \mathrm{mg} / \mathrm{kg})$, IH $(20 \mathrm{mg} / \mathrm{kg})$ or a combination of these for 80 days. Kaplan-Meir survival analysis showed that the median survival time of the vehicle control group $(n=10)$ was approximately 34 days. Exposing mice only to CQ or IH resulted in mild increases in their survival time (36 or 39 days, $n=10$ ). However, a combination of $\mathrm{CQ} / \mathrm{IH}$ significantly improved the median survival of the mice to 62 days $(P<0.001$ compared to the vehicle control) (Fig. 6a). We next determined the effect of the $\mathrm{CQ} / \mathrm{IH}$ combination on the tumor growth of the TNBC xenografts. CQ itself had no significant impact on tumor growth and $\mathrm{IH}$ treatment modestly inhibited tumor growth; however, a combination of $\mathrm{CQ} / \mathrm{IH}$ caused greater inhibition of tumor growth $(P<0.001$, compared to the vehicle control) (Fig. $6 \mathrm{~b})$. No statistically significant changes in body weight were noted in either vehicle control, $\mathrm{CQ}, \mathrm{IH}$, or the combination (Fig. 6c).

We next examined the morphological changes, apoptosis, and CaMKII/Drp1 signaling pathway in the tumor tissue of the TNBC xenografts using H\&E staining, TUNEL, and immunohistochemistry analyses. Whereas CQ itself had little effect on morphological changes and $\mathrm{IH}$ treatment led to modest decreases in the number of cancer cells, the combination of $\mathrm{CQ} / \mathrm{IH}$ dramatically decreased the number of cancer cells and exhibited signs of the infiltration of inflammatory cells and apoptosis (Fig. 6d, top panels). The TUNEL and immunohistochemistry analyses showed modest increases in apoptosis and cleaved caspase 3 in tumor sections of mice treated with $\mathrm{IH}$ alone, and a significant increase in apoptosis and cleaved caspase 3 in tumor sections of mice treated with $\mathrm{CQ} / \mathrm{IH}$ (Fig. 6d, second and third panels). Furthermore, combined treatment with $\mathrm{CQ} / \mathrm{IH}$ led to significant increases in the interaction of CaMKII and Drp1 (Fig. $6 \mathrm{~d}$, fourth panel). Taken together, these findings indicate a combination of $\mathrm{CQ} / \mathrm{IH}$ inhibited tumor growth and induced apoptosis TNBC xenograft in vivo through interruption of CaMKII/Drp1 signaling.

\section{Discussion}

In this study, we provide, for the first time, compelling evidence that inhibition of autophagy/mitophagy selectively potentiates $\mathrm{IH}$-induced mitochondrial fission and apoptosis in TNBC cells. Increasing evidence reveals the close relationship between autophagy and apoptosis [33-35]. Inhibition of autophagy often causes excessive autophagy (e.g. increased amounts of both LC3-II and p62). This leads to autophagic stress, and ultimately, apoptosis [33]. In the present study, we found that inhibition of autophagy by CQ potently enhanced $\mathrm{IH}$-induced 


\section{A}

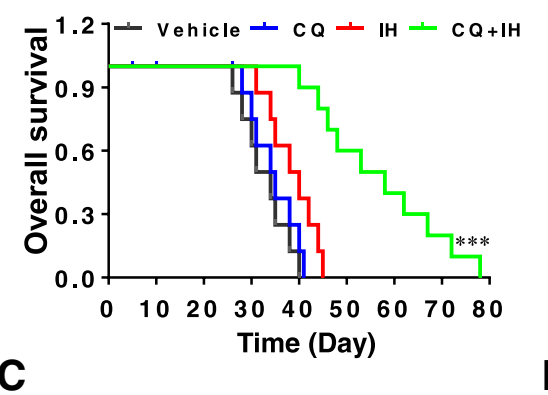

B

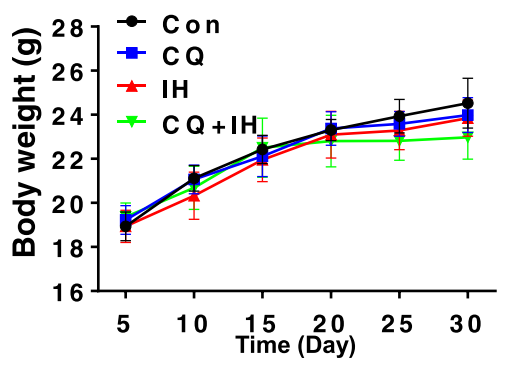

D
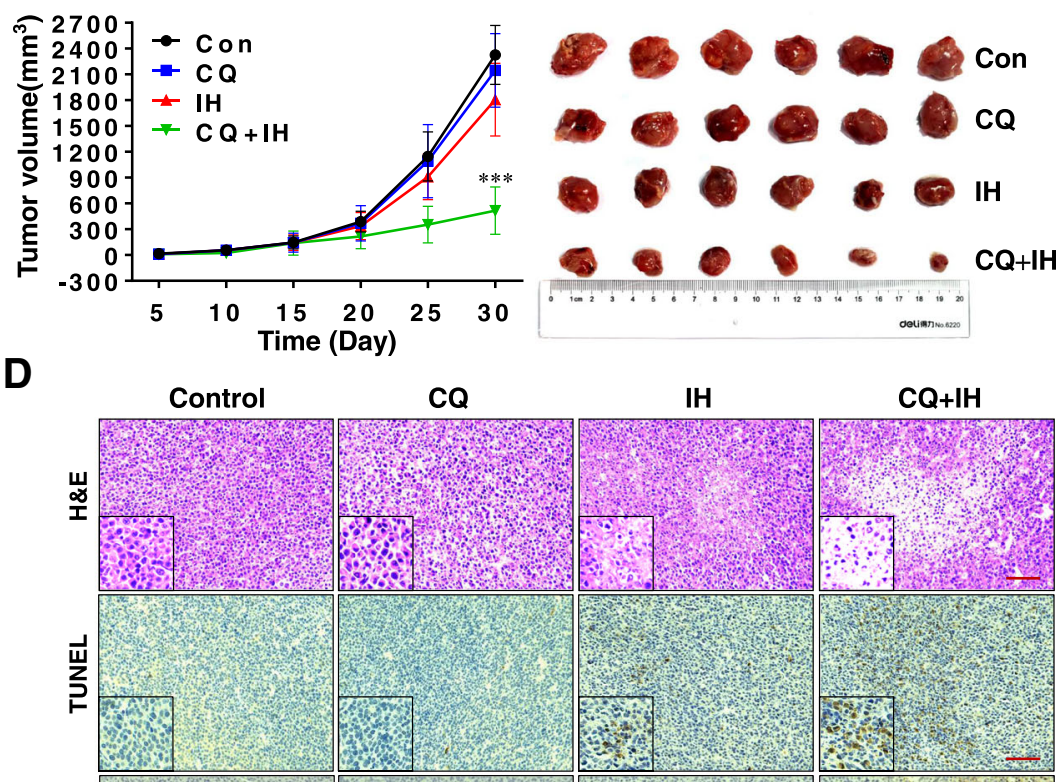

E
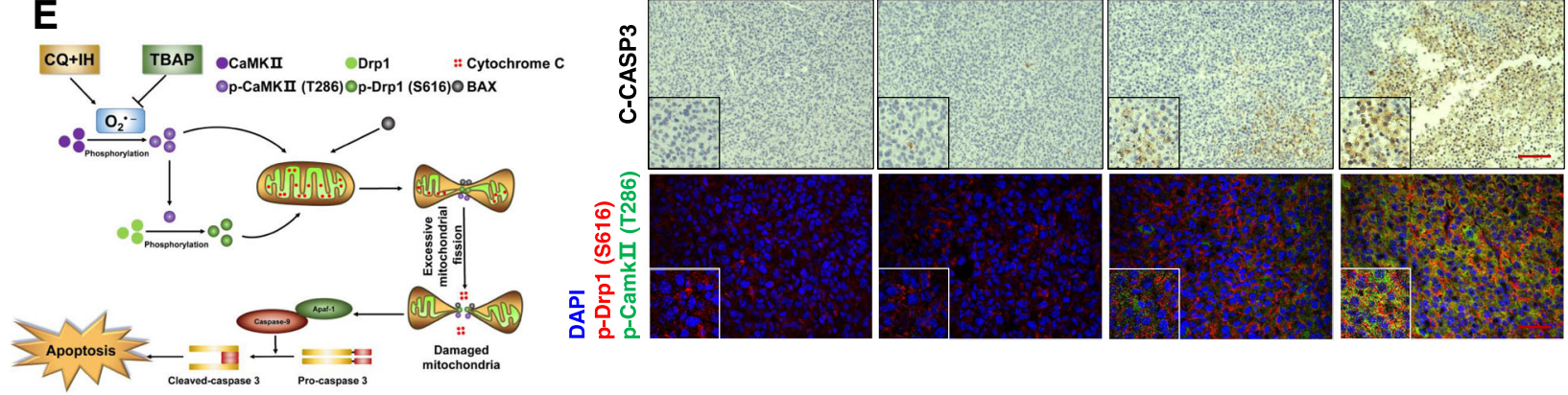

Fig. 6 The combination of $C Q / H$ inhibits tumor growth in a TNBC xenograft mouse model. Sixty-four BALB/c nude mice were inoculated subcutaneously with MDA-MB-231 cells and randomly divided into four groups (16 mice per group, ten mice were used for determination of survival and six for determination of tumor volume and H\&E, TUNEL, and immunohistochemistry analyses). After 5 days of inoculation, mice were treated with vehicle, $C Q, I H$, and the $C Q / H$ combination. a Comparison of the overall survival of mice between vehicle, $C Q, H$ and $C Q / H$ ( $n=10$ mice per group). Statistical significance in survival was determined by log-rank test. ${ }^{* * *} P<0.01$, comparison between vehicle and $\mathrm{CQ} / \mathrm{IH}$. b Average tumor volume in mice treated with vehicle, $\mathrm{CQ}, \mathrm{IH}$, and $\mathrm{CQ} / \mathrm{IH}\left(n=6\right.$ mice per group). ${ }^{* * *} P<0.001$, comparison between vehicle and $\mathrm{CQ} / \mathrm{IH}$. c Body weight of mice during the 30 days of treatment. d Tumor tissues were sectioned and subjected to H\&E, TUNEL, and immunohistochemistry analyses for determination of morphology, apoptosis, and the expression of C-Caspase 3, p-CaMKII (T286), and p-Drp1 (S616). Original magnification $\times 200$. Scale bars: $100 \mu \mathrm{m}$. e The proposed mechanism of the synergistic interactions between isorhamnetin and chloroquine

cell death. It is more likely that the excessive autophagosome accumulation could be involved in synergistic interactions between CQ and IH in mediating cell death based on the following observations. The first is that the combination of CQ and IH led to an increased accumulation of autophagosomes (e.g. increased amounts of both LC3-II and p62 in mitochondria and increased accumulation of mitophagosomes). Secondly, partially blocking autophagosome formation with siRNA against ATG5 markedly attenuated combination-mediated increased amounts of LC3-II in mitochondria and accumulation of mitophagosomes. The third was that the knockdown of ATG5 abrogated combination-induced PARP degradation, caspase-3 activation, cytochrome c release, and apoptosis. These findings suggest that the $\mathrm{CQ} / \mathrm{IH}$ combination inducing cell death depends largely on excessive autophagy.

In particular, we demonstrated the inhibition of autophagy/mitophagy by CQ-sensitized TNBC cells to IH-induced cell death through Drp1-dependent mitochondrial fission. Drp1 is a member of the conserved dynamin GTPase superfamily, which includes a broad range of membrane fission proteins [36]. During mitochondrial fission, Drp1 is translocated from the cytosol to prospective fission sites on the mitochondria [37]. Mitochondrial fission leads to cytochrome $\mathrm{c}$ release and the activation of caspases, which can ultimately lead to 
cell death [38]. Drp1 is one of the main regulators of mitochondrial fission, and its recruitment to mitochondria is tightly regulated by posttranslational modifications such as phosphorylation, S-nitrosylation, SUMOylation, and ubiquitination [39]. Among these modifications on Drp1, phosphorylation has been most extensively studied. Drp1-dependent mitochondrial fragmentation is controlled by phosphorylation at two different conserved sites, serine 616 and 637 [40]. The two sites seem to have opposing effects on mitochondrial shape [41, 42]. While Drp1 phosphorylation at S616 promotes mitochondrial fission, Drp1 phosphorylation at S637 suppresses it [24]. In this study, we demonstrate that the phosphorylation of Drp1 at S616 and its mitochondrial translocation are essential for mitochondrial fission and apoptosis mediated by the combination of $\mathrm{CQ} / \mathrm{IH}$ based on multiple lines of evidence. The first is that the combination of $\mathrm{CQ} / \mathrm{IH}$ led to phosphorylation of Drp1 at S616 but did not affect phosphorylation of Drp1 at S637. The second is that the combination of $\mathrm{CQ} / \mathrm{IH}$ caused the mitochondrial translocation of Drp1. Our study also showed that the combination of $\mathrm{CQ} / \mathrm{IH}$ caused the mitochondrial translocation of Bax. Increasing evidence reveals that, in response to apoptotic stimuli, mitochondrial translocation of Bax is essential for mitochondrial outer membrane permeabilization (MOMP) and the ensuing release of cytochrome c [43]. Drp1 has previously been reported to be critical for cytochrome c release and apoptosis [44]. A more likely possibility is that Drp1 might interact directly with activated Bax, creating a complex that is more active in MOMP, mitochondrial fission, and cytochrome c release [45]. Consistent with this, our finding indicates that Drp1 is colocalized with Bax at mitochondrial fission sites during the combination of $\mathrm{CQ} / \mathrm{IH}$ mediating cytochrome $\mathrm{c}$ release and apoptosis. Thus, these findings indicate that the phosphorylation of Drp1 (S616) and its mitochondrial translocation is critical for mitochondrial fission, cytochrome c release, and apoptosis in TNBC cells in response to the combination of $\mathrm{CQ} / \mathrm{IH}$.

This study also provides evidence that the activation of calmodulin-dependent protein kinase II (CaMKII) is crucial to combination-induced mitochondrial fission and apoptosis in TNBC cells. CaMKII is a multifunctional serine/threonine protein kinase that plays an important role in the transmission of $\mathrm{Ca}^{2+}$ signals to regulate various cellular processes $[46,47]$. In a recent study, the activation of CaMKII and the subsequent phosphorylation of Drp1 at S616 are critical for mitochondrial fission during chronic $\beta$-adrenergic stimulation [26]. It has also been demonstrated that CaMKII mediates radiation-induced mitochondrial fission by regulating the phosphorylation of Drp1 at S616 [37]. Consistent with these results, the induction of mitochondrial fission and apoptosis by the combination of $\mathrm{CQ} / \mathrm{IH}$ was associated with the activation of CaMKII mediating phosphorylation (S616) and the mitochondrial translocation of Drp1. Firstly, combined treatment with $\mathrm{CQ} / \mathrm{IH}$ induces the phosphorylation of CaMKII (Thr286) and Drp1(S616). Secondly, mitochondrial translocation of Drp1, mitochondrial fission, and apoptosis were blocked in cells overexpressing CaM$\mathrm{KII}^{\mathrm{T} 286 \mathrm{~A}}$ (occluding Thr286 phosphorylation) but promoted in cells overexpressing CaMKII ${ }^{\mathrm{T} 286 \mathrm{D}}$ (mimicking Thr286 phosphorylation) in response to the CQ/IH combination. Thirdly, the knockdown of CaMKII with siRNA significantly blocked the mitochondrial translocation of Drp1, mitochondrial fission, and apoptosis mediated by the combination of $\mathrm{CQ} / \mathrm{IH}$. Very surprisingly, we discovered that the $\mathrm{CQ} / \mathrm{IH}$ combination led to the mitochondrial translocation of CaMKII. It is much more possible that the phosphorylation of CaMKII (Thr286) and its mitochondrial translocation may serve as switches which determine the phosphorylation (S616) and mitochondrial translocation of Drp1 during mitochondrial fission and apoptosis induced by the $\mathrm{CQ} / \mathrm{IH}$ combination, as shown by a variety of evidence. The first is that the combination of $\mathrm{CQ} / \mathrm{IH}$ led to the phosphorylation of both CaMKII (Thr286) and Drp1 (S616) and their mitochondrial translocation. Secondly, the combination of $\mathrm{CQ} / \mathrm{IH}$ promoted the interaction and colocalization of CaMKII and Drp1 in the mitochondria. Thirdly, the mitochondrial translocation of CaMKII and Drp1, mitochondrial fission, and apoptosis were blocked in cells overexpressing CaM$\mathrm{KII}^{\mathrm{T} 286 \mathrm{~A}}$ but promoted in cells overexpressing CaM$\mathrm{KII}^{\mathrm{T} 286 \mathrm{D}}$, in response to the combination $\mathrm{CQ} / \mathrm{IH}$. The final piece of evidence is that the knockdown of CaMKII with siRNA significantly blocked the mitochondrial translocation of CaMKII and Drp1, mitochondrial fission, and apoptosis mediated by the $\mathrm{CQ} / \mathrm{IH}$ combination. To the best of our knowledge, this is the first report finding that the mitochondrial translocation of CaMKII is required for combination-mediated Drp1-dependent mitochondrial fission and cell death.

Several lines of evidence demonstrate that ROS play critical roles in CaMKII activation-mediated apoptosis [48-51]. ROS, including $\mathrm{O}_{2}{ }^{-*}, \mathrm{H}_{2} \mathrm{O}_{2}$, and $\mathrm{OH} \cdot$, are recognized as signaling molecules that are mobilized in response to various apoptotic stimuli [52]. In this study, we employed three antioxidants-TBAP, catalase, and sodium formate, which primarily act on $\mathrm{O}_{2}{ }^{-}, \mathrm{H}_{2} \mathrm{O}_{2}$, and $\mathrm{OH}$, respectively-to investigate the involvement of individual ROS in combination-mediated mitochondrial fission, apoptosis, and perturbations in signaling events. Our results suggest that $\mathrm{O}_{2}{ }^{-}$- plays an essential role in combination-mediated apoptosis in TNBC cells, based on several lines of evidence. The first is that TBAP, a $\mathrm{O}_{2}{ }^{-}$ scavenger, essentially abrogated $\mathrm{CQ} / \mathrm{IH}$-mediated ROS generation in TNBC cells, whereas catalase $\left(\mathrm{a}_{2} \mathrm{H}_{2}\right.$ 
scavenger) and SF (a OH. scavenger) failed to do so. Secondly, TBAP, but not catalase and SF, noticeably prevented phosphorylation of CaMKII (Thr286) and Drp1 (S616) and their mitochondrial translocation mediated by $\mathrm{CQ} /$ IH. Thirdly, TBAP, but not catalase and SF, markedly attenuated colocalization of CaMKII and Drp1 at mitochondria induced by $\mathrm{CQ} / \mathrm{IH}$. Finally, TBAP, but not catalase and SF, significantly inhibited mitochondrial fission and apoptosis mediated by $\mathrm{CQ} / \mathrm{IH}$. Together, these findings suggest that $\mathrm{O}_{2}{ }^{-}$is primarily responsible not only for $\mathrm{CQ} / \mathrm{IH}$-mediated lethality in TNBC cells but also for perturbations in the CaMKII/Drp1 signaling pathway.

\section{Conclusions}

In summary, the present findings demonstrate for the first time that the inhibition of autophagy/mitophagy by $\mathrm{CQ}$ enhanced $\mathrm{IH}$-mediated apoptosis by triggering mitochondrial fission in TNBC cells. Our findings highlight a critical role of ROS-mediating CaMKII/ Drp1 signaling in the regulation of mitochondrial fission and apoptosis induced by the combination of $\mathrm{CQ} / \mathrm{IH}$. These findings support a hypothetical model of the synergistic effects of $\mathrm{CQ} / \mathrm{IH}$ (Fig. 6e). In this model, the $\mathrm{CQ} / \mathrm{IH}$ combination induces production of ROS, particularly the $\mathrm{O}_{2}{ }^{*-}$ free radical. This, in turn, promotes the phosphorylation of CaMKII/Drp1 and their mitochondrial translocation, leading to the mitochondrial translocation of Bax; this culminated in mitochondrial fission, caspase activation, and apoptosis. Our findings also suggest that IH has the potential for further development as a novel chemotherapeutic agent, and that a combination of $\mathrm{IH}$ with classic autophagy/mitophagy inhibitor could represent a novel therapeutic strategy for the treatment of TNBC.

\section{Additional file}

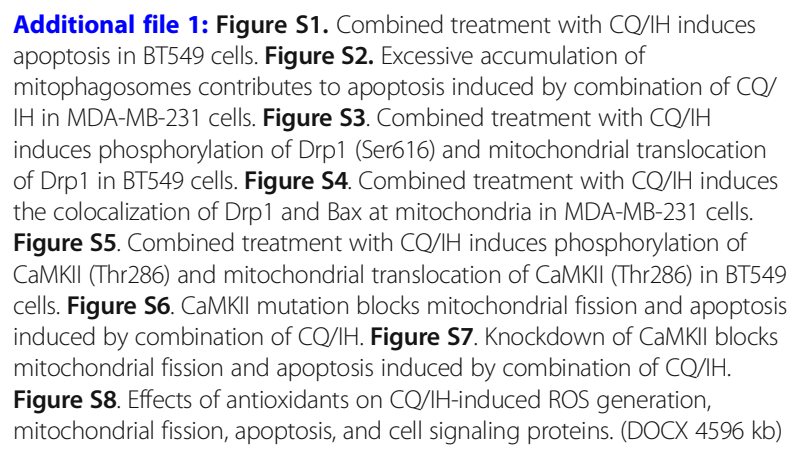

\section{Abbreviations}

CaMKII: Calmodulin-dependent protein kinase II; CQ: Chloroquine; Drp1: Dynamin-related protein 1; $1 \mathrm{H}$ : Isorhamnetin; ROS: Reactive oxygen species; TNBC: Triple-negative breast cancer

\section{Acknowledgements}

This work was funded by National Natural Science Foundation of China (31571425, 81402970; 81402013).

\section{Funding}

See acknowledgements.

\section{Availability of data and materials}

All data generated or analyzed during this study are included in this published article and its supplementary information files.

\section{Authors' contributions}

NG. Designed the study and wrote manuscript. JH. Designed the study, performed all the experiments, and analyzed and interpreted the data. YZ. Performed the experiments and revised manuscript. XJ. Performed the experiments (Cell culture and flow cytometry). HZ. Performed the experiments (Identified the structure of $\mathrm{IH}, \mathrm{MTT}$ assay). ZG. Edited manuscript. YL. Performed the experiments (Western blot). RF. Performed the experiments (IP and immunofluorescence). LL. Performed the experiments (Apoptosis detection). JL. Performed the experiments (MTT assay). HC. Designed the study and provided critical revision and intellectual content. All authors read and approved the final manuscript.

\section{Ethics approval}

The animal experiments conducted strictly in accordance with the Animal Study Guidelines of Army Medical University.

\section{Consent for publication}

Not applicable.

\section{Competing interests}

The authors declare that they have no competing interests.

\section{Publisher's Note}

Springer Nature remains neutral with regard to jurisdictional claims in published maps and institutional affiliations.

\section{Author details}

${ }^{1}$ College of Pharmacy, Army Medical University, 30 Gaotanyan Street, Shapingba District, Chongqing 400038, China. ${ }^{2}$ Key Laboratory of Basic Pharmacology of Ministry of Education and Joint International Research Laboratory of Ethnomedicine of Ministry of Education, Zunyi Medical University, Zunyi, China. ${ }^{3}$ Greater Philadelphia Pharmacy, Philadelphia, USA. ${ }^{4}$ State Key Laboratory of Silkworm Genome Biology, Southwest University, 2\#Tiansheng Road, Beibei District, Chongqing 400716, China. ${ }^{5}$ Medical Research Institute, Southwest University, 2\#Tiansheng Road, Beibei District, Chongqing 400716, China.

Received: 18 February 2019 Accepted: 30 April 2019

Published online: 28 May 2019

\section{References}

1. Nagini S. Breast Cancer: current molecular therapeutic targets and new players. Anti Cancer Agents Med Chem. 2017;17:152-63.

2. Dietze EC, Sistrunk C, Miranda-Carboni G, O'Regan R, Seewaldt VL. Triplenegative breast cancer in African-American women: disparities versus biology. Nat Rev Cancer. 2015;15:248-54.

3. Yao H, He G, Yan S, Chen C, Song L, Rosol TJ, Deng X. Triple-negative breast cancer: is there a treatment on the horizon? Oncotarget. 2017;8:1913-24.

4. Wu N, Zhang J, Zhao J, Mu K, Zhang J, Jin Z, Yu J, Liu J. Precision medicine based on tumorigenic signaling pathways for triple-negative breast cancer. Oncol Lett. 2018;16:4984-96.

5. Chun KH, Park JH, Fan S. Predicting and overcoming chemotherapeutic resistance in breast Cancer. Adv Exp Med Biol. 2017;1026:59-104.

6. Nunez C, Capelo JL, Igrejas G, Alfonso A, Botana LM, Lodeiro C. An overview of the effective combination therapies for the treatment of breast cancer. Biomaterials. 2016;97:34-50.

7. Limpert AS, Lambert LJ, Bakas NA, Bata N, Brun SN, Shaw RJ, Cosford NDP. Autophagy in Cancer: regulation by small molecules. Trends Pharmacol Sci. 2018:39:1021-32. 
8. Sun CY, Zhang QY, Zheng GJ, Feng B. Autophagy and its potent modulators from phytochemicals in cancer treatment. Cancer Chemother Pharmacol. 2018

9. Pagotto A, Pilotto G, Mazzoldi EL, Nicoletto MO, Frezzini S, Pasto A, Amadori A. Autophagy inhibition reduces chemoresistance and tumorigenic potential of human ovarian cancer stem cells. Cell Death Dis. 2017;8:e2943.

10. Thomas S, Sharma N, Golden EB, Cho H, Agarwal P, Gaffney KJ, Petasis NA, Chen TC, Hofman FM, Louie SG, Schonthal AH. Preferential killing of triplenegative breast cancer cells in vitro and in vivo when pharmacological aggravators of endoplasmic reticulum stress are combined with autophagy inhibitors. Cancer Lett. 2012;325:63-71.

11. Lefort S, Joffre C, Kieffer Y, Givel AM, Bourachot B, Zago G, Bieche I, Dubois T, Meseure $D$, Vincent-Salomon A, et al. Inhibition of autophagy as a new means of improving chemotherapy efficiency in high-LC3B triple-negative breast cancers. Autophagy. 2014;10:2122-42.

12. Yeh SL, Lin YC, Lin YL, Li CC, Chuang CH. Comparing the metabolism of quercetin in rats, mice and gerbils. Eur J Nutr. 2016;55:413-22.

13. Ruan Y, Hu K, Chen H. Autophagy inhibition enhances isorhamnetininduced mitochondriadependent apoptosis in nonsmall cell lung cancer cells. Mol Med Rep. 2015;12:5796-806.

14. Ma G, Yang C, Qu Y, Wei H, Zhang T, Zhang N. The flavonoid component isorhamnetin in vitro inhibits proliferation and induces apoptosis in Eca-109 cells. Chem Biol Interact. 2007;167:153-60.

15. Ramachandran L, Manu KA, Shanmugam MK, Li F, Siveen KS, Vali S, Kapoor $S$, Abbasi T, Surana R, Smoot DT, et al. Isorhamnetin inhibits proliferation and invasion and induces apoptosis through the modulation of peroxisome proliferator-activated receptor gamma activation pathway in gastric cancer. J Biol Chem. 2012;287:38028-40.

16. Saud SM, Young MR, Jones-Hall YL, lleva L, Evbuomwan MO, Wise J, Colburn NH, Kim YS, Bobe G. Chemopreventive activity of plant flavonoid isorhamnetin in colorectal cancer is mediated by oncogenic Src and betacatenin. Cancer Res. 2013;73:5473-84.

17. Kim JE, Lee DE, Lee KW, Son JE, Seo SK, Li J, Jung SK, Heo YS, Mottamal M, Bode AM, et al. Isorhamnetin suppresses skin cancer through direct inhibition of MEK1 and PI3-K. Cancer Prev Res (Phila). 2011;4:582-91.

18. Hu S, Huang L, Meng L, Sun H, Zhang W, Xu Y. Isorhamnetin inhibits cell proliferation and induces apoptosis in breast cancer via Akt and mitogenactivated protein kinase kinase signaling pathways. Mol Med Rep. 2015;12:6745-51.

19. Zhang HW, Hu JJ, Fu RQ, Liu X, Zhang YH, Li J, Liu L, Li YN, Deng Q, Luo QS, et al. Flavonoids inhibit cell proliferation and induce apoptosis and autophagy through downregulation of PI3Kgamma mediated PI3K/ AKT/mTOR/p70S6K/ULK signaling pathway in human breast cancer cells. Sci Rep. 2018:8:11255.

20. Gao N, Kramer L, Rahmani M, Dent P, Grant S. The three-substituted indolinone cyclin-dependent kinase 2 inhibitor 3-[1-(3H-imidazol-4-yl)-meth(Z)-ylidene]-5-methoxy-1,3-dihydro-indol-2-one (SU9516) kills human leukemia cells via down-regulation of Mcl-1 through a transcriptional mechanism. Mol Pharmacol. 2006;70:645-55.

21. Li G, Zhou J, Budhraja A, Hu X, Chen Y, Cheng Q, Liu L, Zhou T, Li P, Liu E, Gao N. Mitochondrial translocation and interaction of cofilin and Drp1 are required for erucin-induced mitochondrial fission and apoptosis. Oncotarget. 2015;6:1834-49.

22. Li G, Zhou T, Liu L, Chen J, Zhao Z, Peng Y, Li P, Gao N. Ezrin dephosphorylation/downregulation contributes to ursolic acid-mediated cell death in human leukemia cells. Blood Cancer J. 2013;3:e108.

23. Sheridan C, Delivani P, Cullen SP, Martin SJ. Bax- or Bak-induced mitochondrial fission can be uncoupled from cytochrome C release. Mol Cell. 2008:31:570-85.

24. Archer SL. Mitochondrial dynamics--mitochondrial fission and fusion in human diseases. N Engl J Med. 2013;369:2236-51.

25. Tanaka A, Youle RJ. A chemical inhibitor of DRP1 uncouples mitochondrial fission and apoptosis. Mol Cell. 2008;29:409-10.

26. Xu S, Wang P, Zhang H, Gong G, Gutierrez Cortes N, Zhu W, Yoon Y, Tian R, Wang W. CaMKII induces permeability transition through Drp1 phosphorylation during chronic beta-AR stimulation. Nat Commun. 2016;7:13189.

27. Takemoto-Kimura S, Suzuki K, Horigane SI, Kamijo S, Inoue M, Sakamoto M, Fujii H, Bito H. Calmodulin kinases: essential regulators in health and disease. J Neurochem. 2017;141:808-18.

28. Wagner S, Ruff HM, Weber SL, Bellmann S, Sowa T, Schulte T, Anderson ME, Grandi E, Bers DM, Backs J, et al. Reactive oxygen species-activated ca/ calmodulin kinase IIdelta is required for late I(Na) augmentation leading to cellular Na and ca overload. Circ Res. 2011;108:555-65.
29. Anderson ME. Oxidant stress promotes disease by activating CaMKII. J Mol Cell Cardiol. 2015:89:160-7.

30. Gao N, Rahmani M, Dent P, Grant S. 2-Methoxyestradiol-induced apoptosis in human leukemia cells proceeds through a reactive oxygen species and Akt-dependent process. Oncogene. 2005;24:3797-809.

31. Maghzal GJ, Krause KH, Stocker R, Jaquet V. Detection of reactive oxygen species derived from the family of NOX NADPH oxidases. Free Radic Biol Med. 2012;53:1903-18.

32. Hwang SY, Siow YL, Au-Yeung KK, House J, O K: Folic acid supplementation inhibits NADPH oxidase-mediated superoxide anion production in the kidney. Am J Physiol Renal Physiol 2011; 300:F189-F198.

33. Talukdar S, Pradhan AK, Bhoopathi P, Shen XN, August LA, Windle JJ, Sarkar D, Furnari FB, Cavenee WK, Das SK, et al. MDA-9/Syntenin regulates protective autophagy in anoikis-resistant glioma stem cells. Proc Natl Acad Sci U S A. 2018:115:5768-73.

34. Yoshida GJ. Therapeutic strategies of drug repositioning targeting autophagy to induce cancer cell death: from pathophysiology to treatment. J Hematol Oncol. 2017;10:67.

35. Yoshida GJ. Molecular machinery underlying the autophagic regulation by MDA-9/Syntenin leading to anoikis resistance of tumor cells. Proc Natl Acad Sci U S A. 2018;115:E7652-3.

36. Zhang Z, Liu L, Wu S, Xing D. Drp1, Mff, Fis1, and MiD51 are coordinated to mediate mitochondrial fission during UV irradiation-induced apoptosis. FASEB J. 2016:30:466-76.

37. Bo T, Yamamori T, Suzuki M, Sakai Y, Yamamoto K, Inanami O. Calmodulin-dependent protein kinase II (CaMKII) mediates radiationinduced mitochondrial fission by regulating the phosphorylation of dynamin-related protein 1 (Drp1) at serine 616. Biochem Biophys Res Commun. 2018:495:1601-7.

38. Ban-Ishihara R, Ishihara T, Sasaki N, Mihara K, Ishihara N. Dynamics of nucleoid structure regulated by mitochondrial fission contributes to cristae reformation and release of cytochrome c. Proc Natl Acad Sci U S A. 2013;110:11863-8.

39. Zhou L, Zhang Q, Zhang P, Sun L, Peng C, Yuan Z, Cheng J. C-Abl-mediated Drp1 phosphorylation promotes oxidative stress-induced mitochondrial fragmentation and neuronal cell death. Cell Death Dis. 2017;8:e3117.

40. Chou CH, Lin CC, Yang MC, Wei CC, Liao HD, Lin RC, Tu WY, Kao TC, Hsu CM, Cheng JT, et al. GSK3beta-mediated Drp1 phosphorylation induced elongated mitochondrial morphology against oxidative stress. PLoS One. 2012;7:e49112.

41. Chang CR, Blackstone C. Cyclic AMP-dependent protein kinase phosphorylation of Drp1 regulates its GTPase activity and mitochondrial morphology. J Biol Chem. 2007;282:21583-7.

42. Taguchi N, Ishihara N, Jofuku A, Oka T, Mihara K. Mitotic phosphorylation of dynamin-related GTPase Drp1 participates in mitochondrial fission. J Biol Chem. 2007:282:11521-9.

43. Korytowski W, Basova LV, Pilat A, Kernstock RM, Girotti AW. Permeabilization of the mitochondrial outer membrane by Bax/truncated bid (tBid) proteins as sensitized by cardiolipin hydroperoxide translocation: mechanistic implications for the intrinsic pathway of oxidative apoptosis. J Biol Chem. 2011;286:26334-43.

44. Tang Q, Liu W, Zhang Q, Huang J, Hu C, Liu Y, Wang Q, Zhou M, Lai W, Sheng $\mathrm{F}$, et al. Dynamin-related protein 1-mediated mitochondrial fission contributes to IR-783-induced apoptosis in human breast cancer cells. J Cell Mol Med. 2018;22:4474-85.

45. Montessuit S, Somasekharan SP, Terrones O, Lucken-Ardjomande S, Herzig S, Schwarzenbacher R, Manstein DJ, Bossy-Wetzel E, Basanez G, Meda P, Martinou JC. Membrane remodeling induced by the dynamin-related protein Drp1 stimulates Bax oligomerization. Cell. 2010;142:889-901.

46. Wang $Y Y$, Zhao $R$, Zhe $H$. The emerging role of CaMKIl in cancer. Oncotarget. 2015;6:11725-34

47. Mattiazzi A, Bassani RA, Escobar AL, Palomeque J, Valverde CA, Vila Petroff M, Bers DM. Chasing cardiac physiology and pathology down the CaMKII cascade. Am J Physiol Heart Circ Physiol. 2015;308:H1177-91.

48. Luczak ED, Anderson ME. CaMKII oxidative activation and the pathogenesis of cardiac disease. J Mol Cell Cardiol. 2014;73:112-6.

49. Zhu LJ, Klutho PJ, Scott JA, Xie L, Luczak ED, Dibbern ME, Prasad AM, Jaffer $\mathrm{OA}$, Venema AN, Nguyen EK, et al. Oxidative activation of the ca(2 + )/calmodulin-dependent protein kinase II (CaMKII) regulates vascular smooth muscle migration and apoptosis. Vasc Pharmacol. 2014;60:75-83.

50. Dilshara MG, Jayasooriya R, Molagoda IMN, Jeong JW, Lee S, Park SR, Kim GY, Choi YH. Silibinin sensitizes TRAlL-mediated apoptosis by upregulating 
DR5 through ROS-induced endoplasmic reticulum stress-ca(2+)-CaMKII-Sp 1 pathway. Oncotarget. 2018;9:10324-42.

51. Toledo FD, Perez LM, Basiglio CL, Ochoa JE, Sanchez Pozzi EJ, Roma MG. The ca(2)(+)-calmodulin-ca(2)(+)/calmodulin-dependent protein kinase II signaling pathway is involved in oxidative stress-induced mitochondrial permeability transition and apoptosis in isolated rat hepatocytes. Arch Toxicol. 2014;88:1695-709.

52. Xie R, Gao CC, Yang XZ, Wu SN, Wang HG, Zhang JL, Yan W, Ma TH. Combining TRAlL and liquiritin exerts synergistic effects against human gastric cancer cells and xenograft in nude mice through potentiating apoptosis and ROS generation. Biomed Pharmacother. 2017;93:948-60

Ready to submit your research? Choose BMC and benefit from:

- fast, convenient online submission

- thorough peer review by experienced researchers in your field

- rapid publication on acceptance

- support for research data, including large and complex data types

- gold Open Access which fosters wider collaboration and increased citations

- maximum visibility for your research: over $100 \mathrm{M}$ website views per year

At $\mathrm{BMC}$, research is always in progress.

Learn more biomedcentral.com/submissions 